\title{
Probabilistic methodology for the assessment of the impact of climate change on structural safety
}

\author{
Pietro Croce, Paolo Formichi, Filippo Landi \\ Department of Civil and Industrial Engineering, Structural Division, University of Pisa, Pisa, Italy. E-mail: \\ p.croce@ing.unipi.it
}

\begin{abstract}
Structural design is often governed by climatic actions, such as snow, wind, thermal and atmospheric icing loads, that will occur during the design service life. Since in structural standards climatic actions are usually derived from historical data series assuming stationary climate, alterations induced by climate change should be specifically evaluated, also to assess their influence on structural reliability. In the paper, a probabilistic methodology for the assessment of climate change impact on long-term structural reliability is presented, based on the analysis of observed data series and climate projections, provided by high resolution climate models.

Factor of change uncertainty maps for climate extremes are derived starting from the analysis of weather series generated by an ad hoc weather generator, which considers homogenous populations of data suitably derived from climate model output. The long-term structural reliability is then assessed for reference structures at a given site considering the non-stationary nature of climatic actions by means of the pdfs of changes in extreme value parameters. Specifically, variations of the failure probability with time due to climate change are evaluated by moving time windows of forty years considering changes in mean load intensity and standard deviation of yearly maxima of the investigated climatic action. The results show the capability of the method to assess the impact of climate change on structural safety, highlighting the necessity of adaptation measure to maintain the required target reliability of the structure during its life.
\end{abstract}

Keywords: Climate Change, Climatic Actions, Structural Safety, Reliability.

\section{Introduction}

\subsection{Climate change impact on structural safety}

Structural design is often governed by load effects induced by climatic actions, such as snow, wind, thermal, atmospheric icing, that the structure withstands during its design service life (Croce et al. 2018a). This is particularly the case of lightweight structures, the design of which is mainly dependent on variable actions. As a consequence, variations of climatic actions due to climate change could significantly impact the reliability level of existing structures designed in accordance to the provisions of current or past codes as well as the design of new structures and infrastructures (Croce et al., 2018b).

This aspect is becoming more and more crucial since constructions designed nowadays will face climatic actions and extreme events, which will be unavoidably affected by climate change impact (Madsen, 2013) (Saini and Tien 2017). Indeed, it is expected that climate change effects will become more relevant all around the world, due to the time-delayed impacts of greenhouse gas emissions.

\subsection{Definition of climatic actions in structural Codes}

Climatic actions for structural design are commonly based on the extreme value analysis of past observations of the underlying natural phenomena, under the assumption of stationary climate conditions, disregarding potential effects of climate change. In the verification of the structural performance, characteristic values of the climatic actions are associated with a given probability of exceedance in a reference period. In particular for Europe, as defined in EN1990 (CEN, 2002), characteristic values of climatic actions given in the Eurocodes are associated to a probability of $2 \%$ of the time-varying part being exceeded in one year, leading approximately to a return period of 50 years.

Characteristic values of climatic actions, which are given in structural codes by means of climatic load maps, are derived from the analysis of observed data series generally covering 40-50 years; recorded data are thus not enough extended over time to reflect the effects of the climate change and to predict future trends.

\section{Climate models and scenarios}

Climate models represent the major source of information about future climate. They are process-based dynamical models based on various assumptions, which operate across the entire globe or in a limited region of the world, simulating the physics and chemistry of the atmosphere and oceans to obtain projections of temperature and other key meteorological 
variables. Global Climate Models (GCMs), also known as General Circulation Models, describe several components of the climate system, such as the atmosphere, the ocean, the cryosphere and the land surface, and their interactions. Earth is divided into a series of boxes, called grid cells: the size of the grid cells is the so-called spatial resolution of the model. To limit the computational time, Global Climate Models are characterized by coarse resolution. Since runs of GCMs with finer scale could result too time demanding, Regional Climate Models (RCMs) are currently used to obtain information at a local scale. Starting from the initial and boundary conditions provided by the "driving" GCM, in RCMs sub-GCM grid scale forcing (e.g. complex topographical features and land cover inhomogeneity), are duly considered, on physical basis.

Climate models can be run in different modes and with various objectives, either considering observed changes in atmospheric composition to reproduce historical climate, or according to different scenarios of potential and plausible changes of forcing agents to simulate future climate. These scenarios refer to changes in the emission of greenhouse gasses, which depend on economic and social development, as well as on political choices. The new set of four scenarios reported in (IPCC, 2013) are the so-called Representative Concentration Pathways (RCPs). Each RCP is identified by the level of radiative forcing in $\mathrm{W} / \mathrm{m}^{2}$ expected at the end of the $21^{\text {st }}$ century: e.g. RCP4.5, which is a midrange mitigation emissions scenario, corresponds to a radiative forcing of $4.5 \mathrm{~W} / \mathrm{m}^{2}$ in the year 2100 .

Of course, the representations of the real climate given by the models are inherently uncertain. Therefore, in the analysis of climate projections, three major sources of uncertainty should be duly taken into account: the climate model itself, the expected future scenarios and the internal variability of the climate itself (Hawkins and Sutton 2009),

Unfortunately, the huge computational time required to run these models limits the availability of realizations of each of them, preventing sensitivity analyses.

To improve the statistical representativeness of climate model ensemble and to estimate the uncertainty level in the predictions, an innovative weather generator was developed by the authors in (Croce et al., 2019b), aiming to enlarge the database of climate projections realizations.

\section{Methodology}

The proposed methodology for the assessment of climate change impact on structural safety can be summarized in the following steps:
- collection of high-resolution climate projections of the investigated climate variables for the observation period (to be compared with recorded data for the same period) and for the future period, e.g. daily climate projections for the period 19512100 are provided by the EURO-CORDEX initiative (Jacob et al., 2014) considering different RCPs;

- generation of weather data series from each climate model realization;

- extreme value analysis of weather series in moving time windows of fixed length, in order to derive factors of change for the investigated climate variables;

- assessment of long-term structural reliability considering the non-stationarity of the loads by means of the estimated factors of change.

\subsection{Collection, treatment and analysis of climate projections}

As mentioned before, only few runs of highresolution regional climate model are available, due to the great computational time required. Therefore, in order to obtain a representative sample of climate projections and to quantify the uncertainty in the predictions, the weather generator presented by the authors in (Croce et al., 2019b) is adopted to generate new weather series directly from climate models output. The generated weather data series are obtained by sampling within the homogenous population of data, provided by the climate models, i.e. daily data for a specific month in a period of ten years, introducing adequate physical constraints, based on plausibility checks against past observations.

Once weather data series are generated, they are analysed considering forty-year time windows, shifted by ten years each other (19561995, 1966-2005, 1976-2015, 1986-2025, 19962035, 2006-2045, 2016-2055, 2026-2065, 20362075, 2046-2085, 2056-2095).

The extension of time windows is chosen to be consistent with the actual definition of climatic actions for structural design, which is often based on the analysis of approximately 40 years of past observations.

Annual maxima of the investigated climatic actions are thus extracted for each time window, to evaluate the relevant parameters of the extreme value distribution (EV) and the characteristic values of the action.

\subsection{Evaluation of factor of change uncertainty maps}

The factor of change approach has a long history in climate impact research. It assumes that the change from present to future in the observed 
climate variable $y_{i}$ is the same as the change predicted by the model for that variable.

Therefore, applying the climate change signal estimated from the analysis of climate projections $x_{i}$ to the observations $y_{i}^{p}$, future trends for the same climatic variable $y_{i}^{f}$ can be evaluated as

$$
y_{i}^{f}=y_{i}^{p}+\left(x_{i}^{f}-x_{i}^{p}\right)
$$

or, by considering relative changes, by means of the factor of change $F C$, as

$$
y_{i}^{f}=y_{i}^{p} F C \text { with } F C=\frac{x_{i}^{f}}{x_{i}^{p}}
$$

Mean factors of change can be estimated from the analysis of climate model ensemble, but due to the low number of realizations, it is difficult to obtain a suitable probabilistic description of the predicted changes. In any case, a larger ensemble of weather data series can be obtained by means of the weather generator described in the previous paragraph. Then, evaluating changes for EV parameters and characteristic values, their associated probability can be also assessed.

In this way, factors of change uncertainty maps can be drawn to provide guidance for potential amendments of the current climatic load maps in structural codes. In particular, a convenient representation can be obtained by means of bivariate colour maps as it is shown for extreme rainfall in (Croce et al., 2018c), extreme daily temperatures in (Croce et al., 2019b) and ground snow load in (Croce et al., 2019d).

\subsection{Assessment of long-term structural reliability}

A methodology to estimate time-dependent reliability of aging structures, accounting for the non-stationarity of climatic actions, has been proposed in (Croce et al., 2019b).

The procedure is based on the assessment of factors of change for mean load intensity and standard deviation of annual maxima of the investigated climatic actions. Assuming an EV Type I (EVI) distribution for the climatic action, whose parameters, location and scale, are $\mu(\bar{t})$ and $\sigma(\bar{t})$, respectively, the time-dependent structural reliability results:

$$
\begin{gathered}
L(t)= \\
\exp \left\{-\int_{0}^{t} \lambda(\bar{t})[1-\exp \{-\exp [-Z(\bar{t})]\}] d \bar{t}\right\},
\end{gathered}
$$

where

$$
Z(\bar{t})=\frac{R_{0} D(\bar{t})-\mu(\bar{t})}{\sigma(\bar{t})}
$$

$\lambda(\bar{t})$ is the mean occurrence rate of the action, $R_{0}$ is the initial resistance of the structure and $D(\bar{t})$ is a suitable resistance degradation function.

As mentioned before, the variation of the EVI parameters with time, is assessed for different appropriate time windows, suitable for structural design: forty years long, and shifted by ten years (Croce et al., 2019b).

Considering factors of change at each time window $\bar{t}$ for the mean load intensity, $\bar{q}$, and for the standard deviation, $\sigma_{q}$, of the annual maxima, the variation of EVI parameters with time can be thus estimated as

$$
\begin{gathered}
\mu(\bar{t})=F C_{\bar{q}}(\bar{t}) \bar{q}-0.5772 \frac{\sqrt{6}}{\pi} F C_{\sigma_{q}}(\bar{t}) \sigma_{q}(5) \\
\sigma(\bar{t})=\frac{\sqrt{6}}{\pi} F C_{\sigma_{q}}(\bar{t}) \sigma_{q}
\end{gathered}
$$

Factors of change, $F C_{\bar{q}}(\bar{t})$ and $F C_{\sigma_{q}}(\bar{t})$, are both random variables, that can be described by the empirical distribution functions derived from the analysis of the weather generated series.

\section{Case study}

The following example illustrates an application of the proposed methodology to assess the variation of structural reliability according to the expected snow load trend at a specific location in Italy.

The design criteria and the reliability targets given in the Eurocode EN1990 (CEN, 2002) have been adopted.

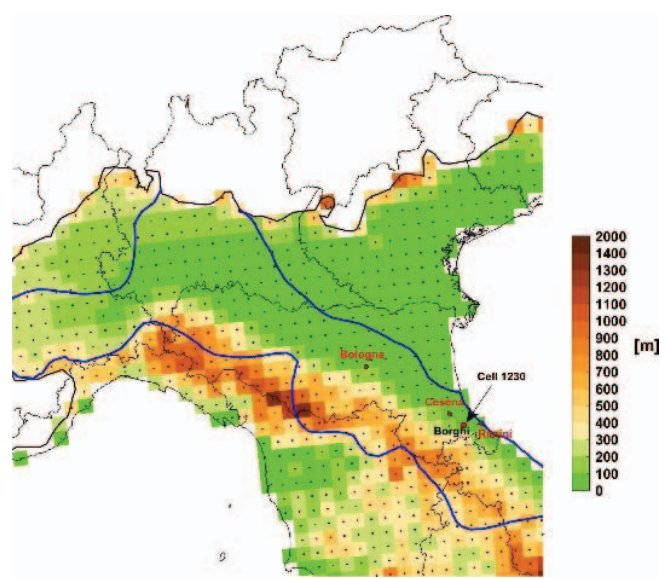

Fig. 1. Location of the Italian investigated cell, in the Zone 3 of the Mediterranean region, in blue, according to EN1991-13 (CEN, 2003).

The investigated Italian cell is located in the Emilia Romagna region and belongs to the Zone 3 of the Mediterranean Region defined by 
EN1991-1-3 (CEN, 2003). The cell, which is sized $12.5 \mathrm{~km}$ and centred close to the small town of Borghi, is shown in Figure 1.

According to the procedure described above, an ensemble of climate projections provided by five high resolution regional climate models, developed by the EURO-CORDEX initiative (Jacob et al., 2014) are analysed for the period 1951-2100, considering two different scenarios, RCP4.5 and RCP8.5. The main characteristics of the investigated climate models are summarized in Table 1 .

Table 1. Overview of the main characteristics of the investigated climate projections.

\begin{tabular}{|c|c|c|c|}
\hline $\begin{array}{c}\text { Meteo } \\
\text { Institute }\end{array}$ & $\mathrm{RCM}^{(1)}$ & $\begin{array}{l}\text { Driving } \\
\mathrm{GCM}^{(2)}\end{array}$ & $\begin{array}{c}\text { Ensemble } \\
\text { member }\end{array}$ \\
\hline CLMcom & CCLM4-8-17 & $\begin{array}{l}\text { CNRM- } \\
\text { CM5-LR }\end{array}$ & rlilp1 \\
\hline CLMcom & CCLM4-8-17 & $\begin{array}{c}\text { EC- } \\
\text { EARTH }\end{array}$ & r12ilp1 \\
\hline KNMI & RACMO22E & $\begin{array}{c}\text { EC- } \\
\text { EARTH }\end{array}$ & rlilp1 \\
\hline MPI-CSC & REMO2009 & $\begin{array}{l}\text { MPI-ESM- } \\
\text { LR }\end{array}$ & rli1p1 \\
\hline $\begin{array}{l}\text { IPSL- } \\
\text { INERIS }\end{array}$ & WRF331F & $\begin{array}{c}\text { IPSL- } \\
\text { CM5A-MR }\end{array}$ & rlilp1 \\
\hline
\end{tabular}

(1) Regional Climate Model

(2) Global Climate Model

Weather data series for maximum and minimum daily temperature and precipitation were generated as described in the previous section.

In the weather generation process, 200 data series were computed per each model, leading to an updated ensemble of 1'000 plausible data series consistent with the starting models' predictions.

From the analysis of each daily data series of temperature and precipitation, annual maxima of ground snow load were thus derived, according to the algorithm developed by the authors and presented in (Croce et al. 2018a, Croce et al. 2018b).

Finally, for each ground snow load data series, factors of change for mean $\left(F C_{\bar{q}}(\bar{t})\right)$ and standard deviation $\left(F C_{\sigma_{q}}(\bar{t})\right)$ of annual maxima were evaluated comparing the results at each time window $\bar{t}$, with the values obtained in the first time window $(\bar{t}=1$, i.e. 1956-1995).

In this way, mean and standard deviation were derived analysing the set of factors of change obtained for each time-window.

Results are shown in Table 2 for the emission scenario RCP4.5 and in Table 3 for the emission scenario RCP8.5.

Looking at Tables 2 and 3 , it must be underlined that even if a reduction of snow load is expected in terms of mean values of annual maxima, the increased variability can lead to higher values of extreme loads, significantly influencing the structural reliability.

Table 2. Factor of change for mean load intensity and standard deviation of annual maxima, and characteristic ground snow load. Scenario RCP4.5.

\begin{tabular}{ccccccc}
\hline Time & \multicolumn{2}{c}{$F C_{\bar{q}}(\bar{t})$} & \multicolumn{2}{c}{$F C_{\sigma_{q}}(\bar{t})$} & \multicolumn{2}{c}{$F C_{q_{k}}(\bar{t})$} \\
window & $\bar{X}$ & $\mathrm{COV}$ & $\bar{X}$ & $\mathrm{COV}$ & $\bar{X}$ & $\mathrm{COV}$ \\
\hline $1966-2005$ & 0.99 & 0.09 & 1.00 & 0.14 & 0.99 & 0.12 \\
$1976-2015$ & 0.99 & 0.14 & 1.11 & 0.24 & 1.06 & 0.19 \\
$1986-2025$ & 0.97 & 0.20 & 1.15 & 0.33 & 1.08 & 0.26 \\
$1996-2035$ & 0.83 & 0.23 & 1.03 & 0.34 & 0.95 & 0.27 \\
$2006-2045$ & 0.78 & 0.27 & 1.01 & 0.36 & 0.92 & 0.30 \\
$2016-2055$ & 0.75 & 0.24 & 0.93 & 0.31 & 0.85 & 0.26 \\
$2026-2065$ & 0.70 & 0.28 & 0.85 & 0.29 & 0.78 & 0.26 \\
$2036-2075$ & 0.64 & 0.28 & 0.83 & 0.31 & 0.75 & 0.26 \\
$2046-2085$ & 0.59 & 0.29 & 0.83 & 0.36 & 0.73 & 0.30 \\
$2056-2095$ & 0.54 & 0.32 & 0.81 & 0.40 & 0.70 & 0.35 \\
\hline
\end{tabular}

Table 3. Factor of change for mean load intensity and standard deviation of annual maxima, and characteristic ground snow load. Scenario RCP8.5.

\begin{tabular}{ccccccc}
\hline Time & \multicolumn{2}{c}{$F C_{\bar{q}}(\bar{t})$} & \multicolumn{2}{c}{$F C_{\sigma_{q}}(\bar{t})$} & \multicolumn{2}{c}{$F C_{q_{k}}(\bar{t})$} \\
window & $\bar{X}$ & COV & $\bar{X}$ & COV & $\bar{X}$ & COV \\
\hline $1966-2005$ & 1.01 & 0.10 & 1.04 & 0.17 & 1.03 & 0.14 \\
$1976-2015$ & 1.03 & 0.17 & 1.15 & 0.22 & 1.11 & 0.19 \\
$1986-2025$ & 1.01 & 0.24 & 1.19 & 0.33 & 1.13 & 0.29 \\
$1996-2035$ & 0.88 & 0.28 & 1.13 & 0.37 & 1.04 & 0.33 \\
$2006-2045$ & 0.82 & 0.31 & 1.15 & 0.37 & 1.02 & 0.32 \\
$2016-2055$ & 0.77 & 0.30 & 1.12 & 0.37 & 0.98 & 0.32 \\
$2026-2065$ & 0.70 & 0.31 & 1.09 & 0.35 & 0.93 & 0.29 \\
$2036-2075$ & 0.61 & 0.40 & 0.94 & 0.31 & 0.79 & 0.28 \\
$2046-2085$ & 0.53 & 0.50 & 0.86 & 0.37 & 0.69 & 0.35 \\
$2056-2095$ & 0.39 & 0.56 & 0.68 & 0.54 & 0.55 & 0.48 \\
\hline
\end{tabular}

As an example, adopting the probabilistic models given in Table 4 and the empirical distribution for factors of change previously defined, the variation over time of the structural reliability of a steel component, subjected to both permanent load $G$ and variable load $Q$ (snow load in this case), is discussed in the following.

The steel structure is designed following the classical load and resistance factor design (LRFD) method (Ellingwood et al., 1982).

Combining the loads according formula (6.10) of EN1990 (CEN, 2002)

$$
1.35 G_{k}+1.5 Q_{k}
$$

the minimum characteristic strength $R_{k}$ results 


$$
R_{k}=\gamma_{M}\left(1.35 G_{k}+1.5 Q_{k}\right)
$$

where, according EN1993-1-1 (CEN, 2005), it is $\gamma_{M}=1.00$ for steel.

For the sake of the example, it is assumed $G_{k}=Q_{k}$ as in (Li et al., 2015).

Table 4. Statistical description of structural resistance and loads.

\begin{tabular}{lccc}
\hline \multicolumn{1}{c}{ Variable } & Mean & COV & PDF \\
\hline Initial resistance & $R_{\mathrm{k}}+2 \sigma_{\mathrm{R}}$ & 0.07 & Log- \\
& $G_{\mathrm{k}}$ & 0.10 & Normal \\
Permanent Load & $0.50 Q_{\mathrm{k}}$ & 0.40 & EVI \\
Snow Load & & & \\
\hline
\end{tabular}

Three different cases are considered for the evaluation of time-dependent structural reliability:

- effective protection of the steel structure guaranteed for the whole life (no degradation is assumed),

- $\quad$ no protection, so degradation process starts without delay,

- maintenance interventions, consisting in removal of the rusting layer and painting renewal every 10 years, but degradation due to atmospheric corrosion activated after five years, so that, in each maintenance interval, corrosion penetrates for five years.

Atmospheric corrosion testing for steel generally leads to non-linear kinetics with degradation loss given by an exponential function (Kayser and Nowak, 1989)

$$
C=A t^{B}
$$

where $C$ is the average corrosion penetration, in microns, $t$ is the time in years, and $A$ and $B$ are suitable parameters, depending on the steel type (carbon or weathering) and on the environmental exposure (rural, urban, marine), derived from experimental data by means of regression analysis. Short term exposure non-linear kinetics can be justified considering that corroded layers form a semi-protective corrosion film on the specimen surface, thus reducing the corrosion rate. For long-term exposure, corroded layers can be removed so that linear kinetics of corrosion prevail (Baboian and Dean, 1990). In that case, the use of a power law relationship beyond its range of applicability may seriously underestimate the resulting corrosion damage.

In this study, a linear corrosion model is thus considered, with degradation function

$$
D=1-a t
$$

and rate parameter $a$ assumed equal to 0.001 . The rate parameter was evaluated considering that, in urban environment, in a $10 \mathrm{~mm}$ thick plate of weathering steel corrosion induces a loss of thickness around $1 \mathrm{~mm}$ in 50 years In fact, assuming $A=50.7 \mu \mathrm{m}$ and $B=0.57$ as suggested by (Kayser and Nowak, 1989), eq. 9 provides a thickness loss of approximately $500 \mu \mathrm{m}$ per side in 50 years, corresponding to a $0.1 \%$ loss per year.

In case of maintenance painting, the degradation process acting on the steel thickness is interrupted once the new protective film is applied on the structure.

In Figure 2, the three different conditions concerning resistance degradation are illustrated (no degradation in blue, no maintenance strategy in black, maintenance interventions every 10 years in green).

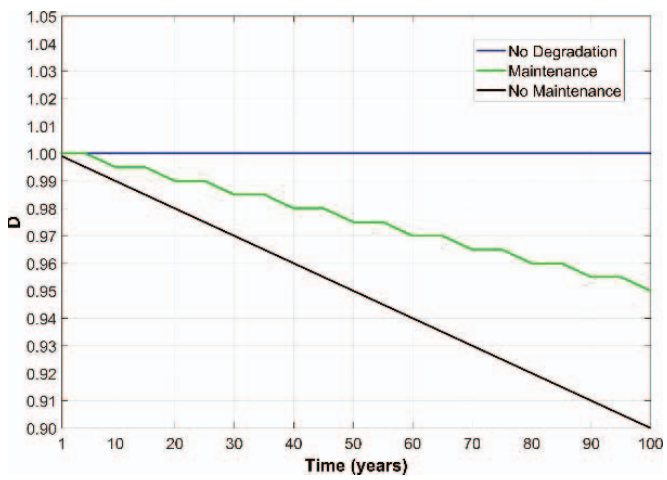

Fig. 2. Three investigated conditions for steel resistance.

Finally, the results of the reliability analysis are shown in Figures 3,4 and 5 in terms of variation of reliability index $\beta$ with time, for the three conditions mentioned above.

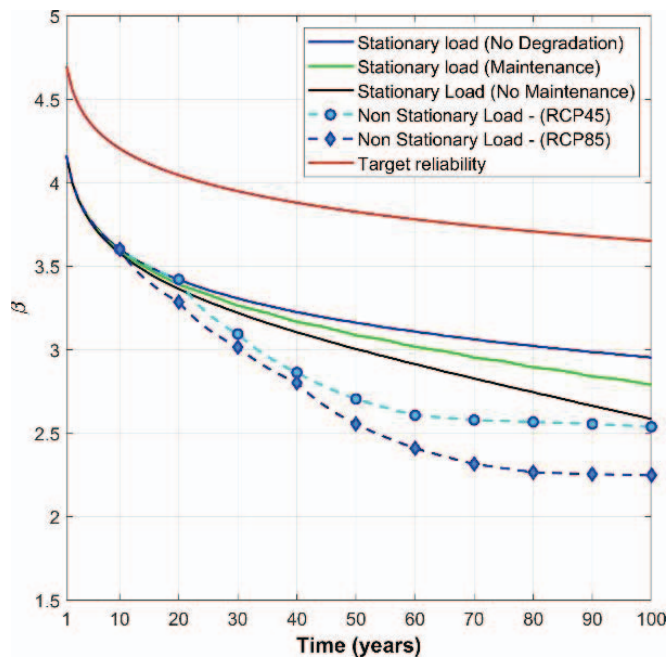

Fig. 3. Variation over time of the reliability index $\beta$, no degradation and non-stationary load. 


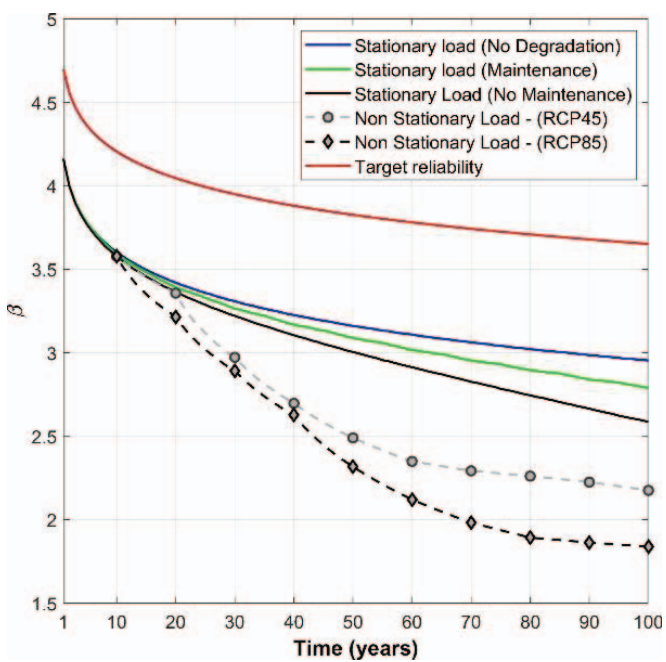

Fig. 4. Variation over time of the reliability index $\beta$, degradation without maintenance and non-stationary load.

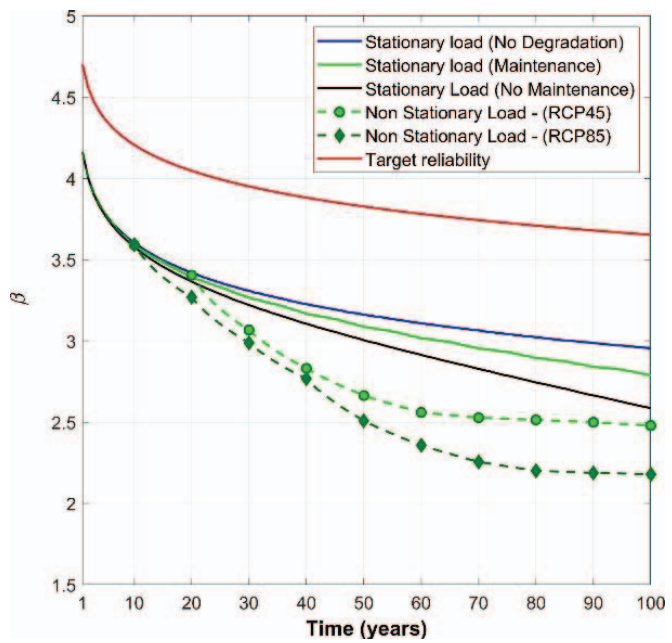

Fig. 5. Variation over time of the reliability index $\beta$, degradation with maintenance interventions every 10 years.

In each Figure, the time-dependent reliability is shown for the three different conditions under the assumption of stationary load (solid lines). Moreover, reliability indexes variation are illustrated for the investigated condition considering non stationary loads given by the medium emission scenario, RCP4.5 and the highest emission scenario RCP8.5 (dashed lines). Reliability curves are thus compared with the target reliability levels (red solid lines).

Inspecting the diagrams in Figures 3 to 5, it clearly appears that climate change can lead to a significant decrease of structural reliability thus calling for adaptation measures (Croce et al., 2019a).
In case that degradation is not relevant, after 50 years the reliability index $\beta$ is 3.16 in case of stationary load; 2.71 in case of RCP4.5 and 2.56 in case of RCP8.5.

In case of degradation and no maintenance, after 50 years $\beta$ is 3.01 in case of stationary load; 2.49 in case of RCP4.5 and 2.32 in case of RCP8.5.

The relevance of a maintenance strategy is thus highlighted by the third condition (Fig. 5) for which reliability indexes increase approaching the values obtained in case of no degradation.

Moreover, since effects of climate change in a long-term future claim for a reduction of snow loads, the reliability index after 60-70 years, depending on the scenario, remains almost constant thus compensating in some way the degradation of the resistance.

Obviously, the conclusions drawn here about the variation of the reliability index are indicative and cannot be generalized.

Moreover, it must be underlined that, to better cover model uncertainties as well as to set a minimum value of load for roof design, often characteristic snow loads given in codes overestimate the loads resulting from the statistical analysis of data, so introducing some additional intentional safety margin as highlighted and discussed in (Croce et al., 2019c).

\section{Conclusions}

A probabilistic methodology for the assessment of climate change impact on relevant climatic actions and long-term structural reliability is presented. The procedure, which is based on the analysis of climate projections, allows to derive factor of change uncertainty maps for climate extremes by means of an ad hoc weather generator implemented directly on climate model output.

The non-stationary of the load is thus taken into account in the assessment of long-term structural reliability evaluating changes for mean load intensity and standard deviation of annual maxima.

In particular, from the analysis of weather generated series, empirical $p d f s$ for factors of change are derived to consider in the assessment of climate change impact the uncertainty in the predictions.

The results of the reliability analysis are presented for a case study of a steel structure in Italy subjected to snow load and considering different degradation conditions and maintenance strategy for the resistance.

The outcomes demonstrate the capability of the methodology and highlight the necessity of 
adaptation measure to maintain the required target reliability of the structure during its life.

\section{References}

Baboian R. and Dean S. W. Corrosion testing and evaluation: silver anniversary volume. Philadelphia, PA: ASTM, c1990.

CEN (2002), EN1990. Eurocode - Basis of Structural Design; Brussels, Belgium.

CEN (2003), EN 1991-1-3. Eurocode 1: Actions on Structures - Part 1-3: General Actions Snow Loads, Brussels, Belgium.

CEN (2005) EN1993-1-1. Eurocode 3: Design of steel structures - Part 1-1: General rules and rules for buildings, Brussels, Belgium.

Croce P., Formichi P., Landi F., Mercogliano P., Bucchigiani E., Dosio A. and Dimova S. (2018a) The snow load in Europe and the climate change. Climate Risk Management 20, 138-154.

Croce P., Formichi P., Landi F. and Marsili F. (2018b). Climate change: Impact on snow loads on structures. Cold Regions Science and Technology 150, 35-50.

Croce P., Formichi P., Landi F. and Marsili F. (2018c). Influence of climate change on extreme values of rainfall. IMSCI 2018 - 12th International Multi-Conference on Society, Cybernetics and Informatics, Proceedings, Volume 1, 2018, pp. 132-137.

Croce P., Formichi P., Landi F. (2019a). Climate Change: Impacts on Climatic Actions and Structural Reliability. Appl. Sci. 2019, 9, 5416.

Croce, P.; Formichi, P.; Landi, F.; Marsili, F. (2019b) Evaluating the effect of climate change on thermal actions on structures. In Caspeele, R., Taerwe, L., Frangopol, D.M. (Eds). pp. 1751-1758, Life-Cycle Analysis and Assessment in Civil Engineering: Towards an Integrated Vision; Taylor \& Francis Group: London, UK,.

Croce, P.; Formichi, P.; Landi, F.; Marsili, F. (2019c). Harmonized European ground snow load map: Analysis and comparison of national provisions. Cold Reg. Sci. Technol., $168,102875$.

Croce P., Formichi P., Landi F. and Marsili F. (2019d). Evaluating the effect of climate change on snow load on structures. IABSE Symposium Guimaraes 2019 - Report, pp.666-673.

Ellingwood, B.; MacGregor, J.G.; Galambos, T.V.; Cornell, C.A. (1982) Probability based load criteria: Load factors and load combinations. J. Struct. Eng., 108, 978-997.

Jacob, D.; et al. (2014). EURO-CORDEX: New high-resolution climate change projections for European impact research. Reg. Environ. Chang., 14, 563-578.

Kayser, J. R.and Nowak, A. S. (1989). Reliability of corroded steel girder bridges. Structural Safety, 6, 53-63.

Hawkins E. and Sutton R.T. (2009). The potential to narrow uncertainty in regional climate predictions. Bull. Am. Meteorol. Soc., 2009, 90(8):1095-1107.

IPCC (2013) Climate Change 2013: The Physical Science Basis. Cambridge University Press: Cambridge, UK

Li, Q.; Wang, C.; Ellingwood, B. (2015) Timedependent reliability of aging structures in the presence of non-stationary loads and degradation. Struct. Saf., 52, 132-141.

Madsen, H.O. (2013) Managing structural safety and reliability in adaptation to climate change. In Deodatis, E.F. (Ed.), 81-88, Safety, Reliability, Risk and Life-Cycle Performance of Structures and Infrastructure; Taylor \& Francis Group: London, UK.

Saini, A., Tien, I. (2017) Impacts of Climate Change on the Assessment of Long-Term Structural Reliability, Journal of Risk and Uncertainty in Engineering Systems, Part A: Civil Engineering 3, . 